\title{
Genetic disruption of $\gamma$-melanocyte- stimulating hormone signaling leads to salt-sensitive hypertension in the mouse
}

\author{
Xi-Ping Ni, ${ }^{1}$ David Pearce, ${ }^{1}$ Andrew A. Butler, ${ }^{2}$ Roger D. Cone, ${ }^{2}$ \\ and Michael H. Humphreys ${ }^{1}$ \\ ${ }^{1}$ Division of Nephrology, San Francisco General Hospital, University of California, San Francisco, \\ San Francisco, California, USA \\ ${ }^{2}$ Vollum Institute, Oregon Health and Science University, Portland, Oregon, USA
}

The $\gamma$-melanocyte-stimulating hormone $(\gamma$-MSH) is a natriuretic peptide derived from the $\mathrm{N}$-terminal region of proopiomelanocortin (POMC). Evidence suggests that it may be part of the coordinated response to a low-sodium diet (LSD). We tested the effect of the HSD $(8 \% \mathrm{NaCl})$ compared with LSD $(0.07 \%)$ on mean arterial pressure (MAP) in mice with targeted disruption of the PC2 gene $\left(P C 2^{-/-}\right)$, necessary for processing of POMC into $\gamma-\mathrm{MSH}$, or the melanocortin receptor 3 gene $\left(\mathrm{Mc}_{3 \mathrm{r}^{-/}}\right.$; the receptor for MSH). In wild-type mice, HSD for 1 week did not alter MAP versus LSD mice, but plasma $\gamma$-MSH immunoreactivity was more than double the LSD value. In contrast, in $P C 2^{-/-}$mice, MAP on the LSD was not greater than in wild-type mice, but plasma $\gamma$-MSH was reduced to one-seventh the wild-type value. On the HSD, MAP rose to a markedly hypertensive level while plasma $\gamma$-MSH concentration remained severely depressed. Intravenous infusion of $\gamma$-MSH $(0.2$ $\mathrm{pmol} / \mathrm{min}$ ) for $30 \mathrm{~min}$ to $\mathrm{PC}^{-/-}$mice after 1 week of HSD lowered MAP from hypertensive levels to normal; infusion of $\alpha-\mathrm{MSH}$ at the same rate had no effect. Injection of $60 \mathrm{fmol}$ of $\gamma$-MSH into the lateral cerebral ventricle of hypertensive mice also lowered MAP to normal. Administration of a stable analogue of $\gamma-\mathrm{MSH}$ intra-abdominally by microosmotic pump to $P C 2^{-/-}$mice prevented the development of hypertension when ingesting the HSD. In mice with targeted disruption of the $M c 3 r$ gene, the HSD also led to marked hypertension accompanied by elevated plasma levels of $\gamma$-MSH; infusion of exogenous $\gamma$-MSH to these mice had no effect on MAP. These results strongly suggest that PC2-dependent processing of POMC into $\gamma$-MSH is necessary for the normal response to the HSD. $\gamma$-MSH deficiency results in marked salt-sensitive hypertension that is rapidly improved with exogenous $\gamma-\mathrm{MSH}$ through a central site of action. $\alpha$-MSH infused at the same rate had no effect on MAP, indicating that the hypertension is a specific consequence of impaired POMC processing into $\gamma-\mathrm{MSH}$. Absence of $\mathrm{Mc} 3 r$ produces $\gamma$-MSH resistance and hypertension on the HSD. These findings demonstrate a novel pathway mediating salt-sensitivity of blood pressure.

J. Clin. Invest. 111:1251-1258 (2003). doi:10.1172/JCI200316993.

Received for publication September 25, 2002, and accepted in revised form January 28, 2003.

Address correspondence to: Michael H. Humphreys, Box 1341, University of California, San Francisco, San Francisco, California 94143, USA. Phone: (415) 476-4104;

Fax: (415) 282-8182; E-mail: mhhsfgh@itsa.ucsf.edu.

Andrew A. Butler's present address is: Pennington Biomedical Research Center, Louisiana State University, Baton Rouge, Louisiana, USA.

Portions of this work were presented at the Annual Meeting of the American Society of Nephrology in Philadelphia,

Pennsylvania, USA, November 1-4, 2002. Portions of this work

have appeared in abstract form (2002. J. Am. Soc. Nephrol. 13:53A).

Conflict of interest: The authors have declared that no conflict of interest exists.

Nonstandard abbreviations used: urinary sodium excretion $\left(U_{\mathrm{Na}} V\right) ; \gamma$-melanocyte-stimulating hormone $(\gamma$-MSH); highsodium diet (HSD); neurointermediate lobe (NIL); proopiomelanocortin (POMC); prohormone convertase 1 (PC1); melanocortin receptor 3 (MC3R); low-sodium diet (LSD); mean arterial pressure (MAP); [Nle $\left.{ }^{3}, \mathrm{D}-\mathrm{Phe}^{6}\right] \gamma-\mathrm{MSH}$ (NDP- $\left.\gamma-\mathrm{MSH}\right)$; plasma renin activity (PRA); trifluoroacetic acid (TFA); A1 (angiotensin 1); atrial natriuretic peptide (ANP).

\section{Introduction}

Numerous neural and humoral systems interact to control total body sodium content, body fluid volumes, and blood pressure through the regulation of urinary sodium excretion $\left(U_{\mathrm{Na}} V\right)$. These include antinatriuretic pathways such as the renin-angiotensin system, aldosterone and sympathetic nerve activity to the kidneys, and natriuretic pathways such as the natriuretic peptide system $(1,2)$. Recent evidence has indicated that other natriuretic systems are involved in regulating $U_{\mathrm{Na}} V$, including dopaminergic activity, the kallikrein-kinin system, and other peptide hormonal pathways (2-4). Among these, evidence has been presented that the natriuretic peptide $\gamma$-melanocyte-stimulating hormone $(\gamma-\mathrm{MSH})$ participates in the integrated response to a high intake of dietary sodium: rats ingesting a high-sodium diet (HSD) for 1 week or longer have a marked increase in plasma $\gamma$ $\mathrm{MSH}$ concentration as well as an increase in the content of $\gamma$-MSH in the neurointermediate lobe (NIL) of the 
pituitary, site of $\gamma$-MSH secretion into the circulation (5, 6). Moreover, the HSD also increases the abundance of proopiomelanocortin (POMC) mRNA in the NIL $(5,6)$; $\mathrm{POMC}$ is the $\mathrm{ACTH} / \beta$-endorphin prohormone, the processing of which in NIL gives rise to $\gamma$-MSH (7). Two enzymes involved in $\mathrm{POMC}$ processing are the protein proconvertases PC1 and PC2 $(7,8)$; in the NIL, their action is carefully regulated in a temporal sequence, with PC1 initially cleaving POMC into the large peptides $\mathrm{ACTH}, \beta$-lipotropin, and a large $\mathrm{N}$-terminal fragment, and PC2 then generating the smaller peptides $\alpha-\mathrm{MSH}$, $\gamma$-MSH, $\beta$-endorphin, and others (7). The mRNA and protein abundance of these enzymes are also coordinately upregulated by the HSD (6). Since physiologic concentrations of $\gamma$-MSH are natriuretic $(9,10)$, these observations in aggregate suggest that this system may participate in the integrated response to circumstances of dietary sodium excess.

The recent availability of mice with targeted disruption of genes relevant to $\gamma$-MSH synthesis and action offers the opportunity to evaluate more definitively the role of this peptide in sodium metabolism $(11,12) . \gamma$-MSH exerts its cellular actions by interacting with one of five identified melanocortin receptors, the MC3R (13), and mice with targeted deletion of this gene have been reported (11). In addition, mice with disruption of the PC2 gene have been described (12); its absence would be predicted to result in $\gamma$-MSH deficiency because it is necessary for the cleavage of larger POMC-derived peptides into $\gamma$-MSH $(7,8)$. We used these genetically altered mouse strains to examine the importance of $\gamma$-MSH in the integrated response to changes in dietary sodium intake. Our results indicate that PC2 deficiency leads to salt-sensitive hypertension that is corrected by infusion of $\gamma$-MSH but not by infusion of the closely related POMC-derived peptide $\alpha$-MSH. MC3R-deficient mice also develop salt-sensitive hypertension, which, in contrast, cannot be corrected by infusion of $\gamma-\mathrm{MSH}$.

\section{Methods}

Mice heterozygous for targeted disruption of the PC2 gene, as described by Furuta et al. (12), were purchased from The Jackson Laboratory (Bar Harbor, Maine, USA), and a breeding colony was established in the transgenic mouse barrier facility at San Francisco General Hospital. These mice were created on a background of C57BL/6J. $\mathrm{PC}^{-/-}$mice exhibit abnormalities in pancreatic islet hormone processing and have significantly reduced blood sugar concentration and slightly reduced growth rates compared with wild-type mice, but are otherwise phenotypically normal (12). A breeding colony was also established using mice heterozygous for deletion of the $M C 3 R$ gene as developed by us (11); these mice were also developed on a C57BL/6J background. The knockout mice exhibit a unique metabolic syndrome characterized by an increase in adipose tissue mass without obesity and with reduced energy expenditure (11). We also established a breeding colony using mice heterozygous for the MC4R gene deletion courteously provided by Dennis Huszar,
Millenium Pharmaceuticals Inc. (Cambridge, Massachusetts, USA) (14). These knockout mice exhibit an obese phenotype with an increase in adipose tissue, hyperphagia, and insulin resistance (14). For each knockout strain, wild-type littermates were used as controls. Mice were housed in cages and fed a nutritionally complete diet with normal $(0.44 \%)$ sodium content until entered into the dietary manipulations described below. All protocols were reviewed and approved by the Committee on Animal Research of University of California, San Francisco.

DNA extraction and PCR amplification. Mice were genotyped at weaning by PCR amplification of DNA extracted from tail tissue using primers described in the original publications $(11,12,14)$. DNA was extracted from tail biopsies using the DNeasy Tissue Kit (QIAGEN Inc., Valencia, California, USA), according to the manufacturer's instructions. Polymerase chain amplification was carried out using HotStarTaq DNA polymerase (QIAGEN Inc.) and the relevant primers for 30 cycles under the cycling conditions reported $(11,12$, 14). Amplification products were electrophoresed on $1.4 \%$ agarose gels and identified by their size (Figure 1 ).

Dietary treatment. Mice 6 weeks of age and older were placed on either the HSD ( $8 \% \mathrm{NaCl}$; Purina Mills Inc., St. Louis, Missouri, USA) or an otherwise nutritionally identical low-sodium diet (LSD; 0.07\%, Purina Mills Inc.) for 7-10 days until they underwent acute study. Acute experimentation. On the day of study, mice were anesthetized with an intraperitoneal injection of ketamine $(100 \mathrm{mg} / \mathrm{kg})$ and xylazine $(15 \mathrm{mg} / \mathrm{kg})$ and placed on a heated operating table. A tracheotomy was performed, the carotid artery identified through a small paratracheal incision, and a tapered polyethylene catheter inserted for measurement of arterial pressure via a P23id Statham blood pressure transducer attached to a direct writing recorder (Model 7D; Grass-Telefactor, West Warwick, Rhode Island, USA). A similar catheter was placed in a femoral vein for infusion of solutions. In some mice a flanged polyethylene catheter was sutured into the dome of the urinary bladder via a suprapubic incision for the timed collection of urine. After completion of this preparative surgery, the mice received an infusion of normal saline containing $2 \mathrm{~g}$ glucose and $2.5 \mathrm{~g}$ BSA per $100 \mathrm{ml}$, $0.7 \%$ body weight over $15 \mathrm{~min}$, to replace surgical fluid losses. This same vehicle solution was infused at 2.5 $\mu \mathrm{l} / \mathrm{min}$ for the duration of the experiment. Blood pressure was then measured over the subsequent $30 \mathrm{~min}$, and an average value of the electrical mean taken as mean arterial pressure (MAP) for that animal. In some experiments, the mice were then exsanguinated, the blood processed as described below, and the animal sacrificed.

In other experiments, the normal saline vehicle was infused intravenously at $2.5 \mu \mathrm{l} / \mathrm{min}$ while urine was collected for $30 \mathrm{~min}$. The intravenous infusion was then changed to vehicle containing $\alpha$-MSH to deliver $0.2 \mathrm{pmol} / \mathrm{min}$ for a second $30-\mathrm{min}$ period. The infusion was changed again to vehicle containing $\gamma-\mathrm{MSH}$ at $0.2 \mathrm{pmol} / \mathrm{min}$ for a third $30-\mathrm{min}$ period, following which a large blood sample was obtained 
and the mouse sacrificed. Urine was collected during each 30-min interval for determination of $U_{\mathrm{Na}} V$, and MAP was determined at the end of each period. In three studies only $\gamma$-MSH was infused.

In an effort to determine the effect of anesthesia on MAP, we studied five MC3R knockout mice fed the HSD for 1 week. They were anesthetized with ketamine/xylazine as described and a catheter placed in the carotid artery. The catheter was then tunneled subcutaneously to exit between the scapulae and secured with a suture. MAP was recorded while the mice were still under anesthesia and then placed in cages until the anesthesia wore off and they were moving freely. MAP was measured again at this time, 6 hours after injection of the anesthesia.

In additional experiments, we tested the effect of $\gamma$-MSH injected directly into the cerebroventricular system of $\mathrm{PC}^{+/+}$and $P C 2^{-/-}$mice fed the HSD for 1 week. Mice were anesthetized as described, a tracheotomy tube placed, and the carotid artery and jugular vein catheterized. The animal was then placed on its ventral surface. The scalp was incised in the midline and a 26gauge needle drilled through the skull to a depth of 2.5 $\mathrm{mm}$, as described by Ackermann and Azizi (15), $0.5 \mathrm{~mm}$ caudal and $1 \mathrm{~mm}$ lateral to the bregma. Placement of the tip of the needle in the lateral ventricle was confirmed at the end of the experiment by injection of $3 \mu \mathrm{l}$ India ink through the needle followed by brain dissection; results from only those mice in which the ink was confined to the ventricular space were accepted for analysis. The experiment was begun $20 \mathrm{~min}$ after the completion of surgery. Baseline MAP was recorded for $10 \mathrm{~min}$, at which time $\gamma$-MSH, $60 \mathrm{fmol}$ in $5 \mu \mathrm{l}$ of normal saline followed by a flush of $10 \mu \mathrm{l}$, was injected intravenously. MAP was observed for another $10 \mathrm{~min}$, when $20 \mathrm{fmol} \gamma$-MSH in a volume of $5 \mu \mathrm{l}$ was injected intracerebroventricularly. MAP was again recorded for 10 min, and a second dose of $\gamma$-MSH, $60 \mathrm{fmol}$ in $5 \mu \mathrm{l}$, was injected. MAP was recorded for a final $10 \mathrm{~min}$, after which the India ink was injected, the mouse sacrificed, and the brain dissected.

Chronic studies. The effect of continuous $\gamma-\mathrm{MSH}$ administration on MAP during ingestion of the HSD was tested in ten $\mathrm{PC}^{-/-}$mice. Under Brevital anesthesia $(50 \mathrm{mg} / \mathrm{kg}$ intraperitoneally), Alzet microosmotic pumps (Model 1007D; Durect Corp., Cupertino, California, USA) were placed intra-abdominally through a midline surgical incision. In half the mice, the pumps were loaded with vehicle while in the other half they were loaded with vehicle containing the stable $\gamma$-MSH analogue $\left[\mathrm{Nle}^{3}, \mathrm{D}-\mathrm{Phe}^{6}\right] \gamma-$ MSH (NDP- $\gamma$-MSH) $(16,17)$ to deliver 12 $\mathrm{pmol} / \mathrm{h}$ in a volume of $0.5 \mathrm{l} / \mathrm{h}$ directly into the peritoneal space. The wounds were closed with sutures and the mice returned to their cages after recovery from anesthesia. They were placed on the HSD, and 1 week later underwent acute experimentation as described above for measurement of MAP.

Figure 1
Radioimmunoassays. Blood was collected in chilled Vacutainer tubes (Becton Dickinson and Co., Franklin Lakes, New Jersey, USA) containing EDTA and 500 KIU aprotinin and centrifuged immediately at $4^{\circ} \mathrm{C}$. The plasma was decanted and stored at $-70^{\circ} \mathrm{C}$ until assayed for $\gamma$-MSH concentration, plasma renin activity (PRA), and plasma aldosterone concentration. For the $\gamma-\mathrm{MSH}$ assay, samples were thawed on ice and extracted through SepColumn chromatography cartridges (Penninsula Laboratories Inc., San Carlos, California, USA); samples from three mice were pooled to obtain sufficient plasma for assay. The cartridges were prepared by wetting with $3 \mathrm{ml}$ of solvent $\mathrm{A}$ - acetonitrile/water/trifluoroacetic acid (TFA; 80:19.9:0.1) - and with $3 \mathrm{ml}$ of 0.1\% TFA. The cartridge was then washed with $10 \mathrm{ml}$ of $0.1 \%$ TFA and eluted with solvent $\mathrm{A}$. Eluates were lyophilized and stored at $-70^{\circ} \mathrm{C}$ until assay, as described previously $(5,6,16)$, using a commercially available RIA kit (Peninsula Laboratories Inc., San Carlos, California, USA) with ${ }^{125} \mathrm{I}-\gamma_{2}-$ MSH as tracer. Results are expressed as femtomoles per milliliter of plasma. The characteristics of this assay have been described (16). PRA was determined in unextracted plasma pooled from two mice by RIA of angiotensin I (A1) generated after incubation of plasma at $37^{\circ} \mathrm{C}$ using a commercial kit (DiaSorin, Stillwater, Minnesota, USA) according to the manufacturer's instructions. Plasma aldosterone concentration was measured in $200 \mu \mathrm{l}$ of unextracted plasma using the DPC Coat-A-Count kit (Diagnostic Products Corp., Los Angeles, California, USA), according to the instructions included in the kit. Statistical analysis. Data are presented as means plus or minus SEM. Analysis was performed using GraphPad InStat software (GraphPad Software Inc., San Diego, California, USA). Comparisons among groups were carried out using one-way or repeated measures ANOVA, as appropriate, with the Bonferroni post-hoc test when significant differences were recognized. Groups that did not have equal standard deviations underwent log transformation of the data before carrying out ANOVA. Comparisons between two groups used the unpaired $t$ test. A $P$ value of less than 0.05 was used to indicate the presence of a significant difference.
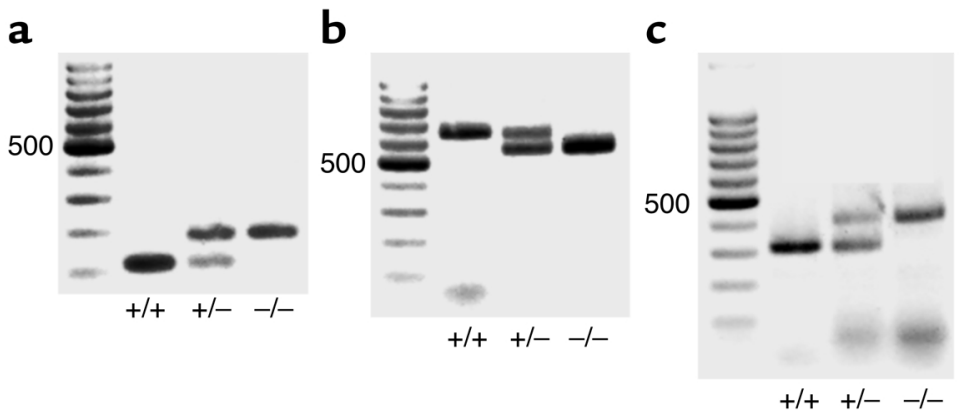

Representative gels showing PCR amplification products for targeted deletions of (a) PC2, (b) Mc3r, and (c) Mc4r genes as described in Methods. +/+, wild type; + /-, heterozygous; -/-, homozygous knockout. Left column is size ladder; 500 indicates $500 \mathrm{bp}$. 

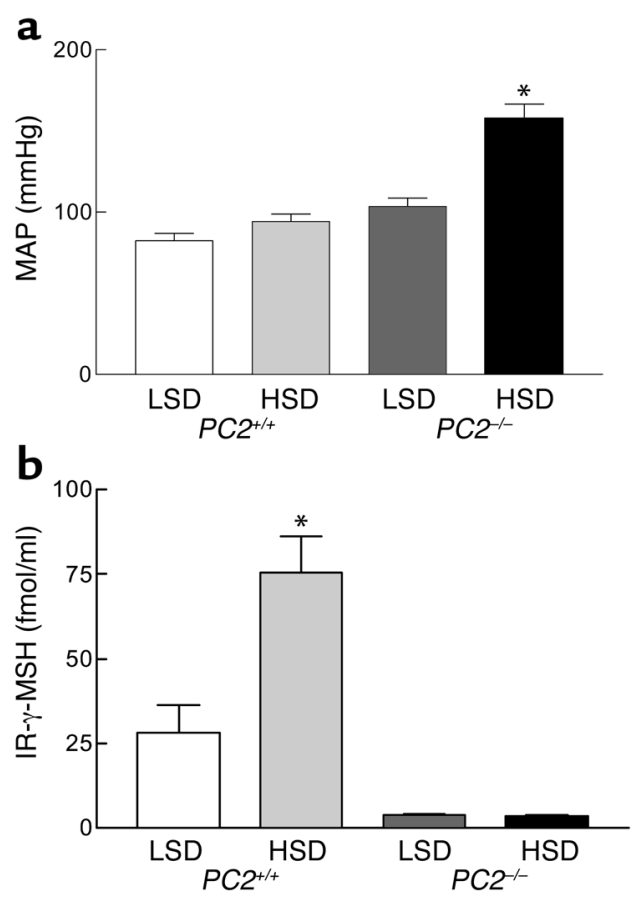

Figure 2

MAP (a) and plasma IR- $\gamma$-MSH concentration (b) after 1 week of a $\mathrm{LSD}$ or $\mathrm{HSD}$ in $\mathrm{PC}^{+/+}$and $P C 2^{-/-}$mice. Results are means $\pm \mathrm{SEM}$ of measurements of MAP in eight mice in each group, as described in Methods, and of IR- $\gamma$-MSH in five samples of plasma, each pooled from three mice. ${ }^{*} P<0.001$ versus all other values.

\section{Results}

Genotyping. Mice underwent genotyping by PCR amplification of DNA extracted from tail biopsies as described in Methods; the results are shown in Figure 1. $\mathrm{PC}^{+/+}$mice exhibited the predicted $117-\mathrm{bp}$ product, whereas $P C 2^{-/-}$mice showed a product of $180 \mathrm{bp}$ and heterozygotes displayed both bands, as reported previously (12) (Figure 1a). $M c 3 r^{+/+}$mice demonstrated an amplification product of $646 \mathrm{bp}$, while Mc3r null mice showed a band of $550 \mathrm{bp}$ (11) (Figure 1b). $\mathrm{Mc} 4 \mathrm{r}^{+/+}$mice showed a product of $313 \mathrm{bp}$, while $M c 4 r^{-/}$mice displayed a product of $405 \mathrm{bp}$ (14) (Figure 1c).

Effect of dietary sodium intake in PC2 ${ }^{-/-}$mice. Results of measurements of MAP and plasma $\gamma$-MSH concentration in $\mathrm{PC}^{-/-}$mice and $\mathrm{PC}^{+/+}$littermates on the LSD and HSD are shown in Figure 2. On the LSD, MAP averaged $83 \pm 5 \mathrm{mmHg}(n=8)$ in wild-type mice and was statistically unchanged in eight other animals ingesting the HSD (94 $\pm 5 \mathrm{mmHg} ; P=\mathrm{NS}$ ) (Figure 2a). In $P C 2^{-/-}$ mice, MAP on the LSD was somewhat elevated compared with wild-type mice on either the LSD or HSD at $104 \pm 5$ $\mathrm{mmHg}$, but this value was not significantly greater (oneway ANOVA, $P<0.10$ ). On the HSD, however, PC2 null mice exhibited a marked increase in MAP to $158 \pm 9$ $\mathrm{mmHg}(P<0.001$ versus all other groups). Thus, PC2 knockout mice exhibit marked salt-sensitive hypertension. These differences in MAP were related to differences in plasma $\gamma$-MSH immunoreactivity. In $\mathrm{PC}^{+/+}$mice, plasma concentration of the peptide was $28.1 \pm 8.1 \mathrm{fmol} / \mathrm{ml}$ during ingestion of the LSD and was markedly increased at $75.6 \pm 10.4 \mathrm{fmol} / \mathrm{ml}$ after a week of the $\operatorname{HSD}(P<0.001)$ (Figure $2 \mathrm{~b}$ ). In contrast, $P C 2^{-/-}$mice on the LSD had a reduced plasma $\gamma$-MSH concentration at $3.9 \pm 0.1 \mathrm{fmol} /$ $\mathrm{ml}\left(P<0.10\right.$ versus $P C 2^{+/+}$mice $)$and did not increase it during ingestion of the HSD $(3.5 \pm 0.3 \mathrm{fmol} / \mathrm{ml} ; P<0.001)$. The HSD leads to a robust increase in plasma $\gamma$-MSH concentration in wild-type mice, just as observed in rats $(5,6)$; absence of PC2 marginally reduces circulating $\gamma$-MSH during ingestion of the LSD and completely prevents the increase expected during ingestion of the HSD. Since these last animals were also hypertensive, these observations raise the possibility that the $\gamma$-MSH deficiency could in some way be linked to the development of the salt-sensitive hypertension.

To determine if $\gamma$-MSH replacement improves MAP in $P C 2^{-/-}$mice fed the HSD for one week, we infused the peptide intravenously as described in Methods. In five mice, a 30-min control period was followed by a 30min infusion of $\alpha-\mathrm{MSH}$ at $0.2 \mathrm{pmol} / \mathrm{min}$, in turn followed by a $30-\mathrm{min}$ infusion of $\gamma-\mathrm{MSH}$; in three additional mice, only $\gamma$-MSH was infused. The results are shown in Table 1 . Infusion of $\alpha-\mathrm{MSH}$ had no effect on MAP or $U_{\mathrm{Na}} V$ compared with the control period. In marked contrast, subsequent infusion of $\gamma$-MSH lowered MAP to the normal range and also approximately doubled $U_{\mathrm{Na}} V$ (Table 1 ). In the three mice infused only with $\gamma$-MSH, MAP fell from $146 \pm 6$ to $103 \pm 2 \mathrm{mmHg}$. Plasma $\gamma$-MSH concentration at the end of the infusion was $165 \pm 28.4 \mathrm{fmol} / \mathrm{ml}$, a value roughly twice that seen in wild-type mice during ingestion of the HSD. In two mice undergoing vehicle infusion only throughout, MAP was unchanged (143-145 and 158-160 mmHg).

We sought to determine if this hypotensive effect of $\gamma$-MSH in hypertensive $P C 2^{-/-}$mice on the HSD occurred

Table 1

MAP and sodium excretion during infusion of $\alpha$ - and $\gamma-\mathrm{MSH}$ in mice after ingestion of the HSD for 1 week

\begin{tabular}{|c|c|c|c|c|c|c|}
\hline & \multicolumn{3}{|c|}{$\mathrm{MAP}, \mathrm{mmHg}$} & \multicolumn{3}{|c|}{$U_{\mathrm{Na}} V, \mathrm{~mol} / \mathrm{min}$} \\
\hline & Control & $\alpha-M S H$ & $\gamma-\mathrm{MSH}$ & Control & $\alpha-\mathrm{MSH}$ & $\gamma-\mathrm{MSH}$ \\
\hline$P C 2^{+/+}$ & $88 \pm 3$ & $86 \pm 2$ & $86 \pm 2$ & $0.83 \pm 0.14$ & $0.72 \pm 0.12$ & $1.37 \pm 0.14^{\mathrm{A}}$ \\
\hline$P C 2^{-/-}$ & $155 \pm 8$ & $150 \pm 8$ & $91 \pm 3^{A}$ & $0.76 \pm 0.13$ & $0.76 \pm 0.19$ & $1.53 \pm 0.17^{\mathrm{A}}$ \\
\hline$M c 3 r^{+/+}$ & $86 \pm 2$ & $86 \pm 2$ & $84 \pm 2$ & $0.46 \pm 0.07$ & $0.51 \pm 0.13$ & $1.20 \pm 0.24^{\mathrm{A}}$ \\
\hline $\mathrm{Mc} \mathrm{r}^{-1-}$ & $145 \pm 2$ & $144 \pm 2$ & $143 \pm 2$ & $0.32 \pm 0.11$ & $0.36 \pm 0.14$ & $0.39 \pm 0.14$ \\
\hline
\end{tabular}

Values are means \pm SE of 4-10 mice per group. ${ }^{A}$ Significantly different from other values in that group, $P<0.01$ or greater by repeated measures ANOVA. 
Table 2

MAP in wild-type and PC2 knockout mice after injection of $\gamma$-MSH into the lateral cerebral ventricle

\begin{tabular}{lcccc}
\hline & Control & $60 \mathrm{fmol}$ iv & $20 \mathrm{fmol}$ icv & $60 \mathrm{fmol} \mathrm{icv}$ \\
$\mathrm{PC2}^{+/+}(n=5)$ & $86 \pm 3$ & $85 \pm 5$ & $82 \pm 5$ & $87 \pm 4$ \\
$\mathrm{PC2}^{-/-}(n=5)$ & $155 \pm 4^{\mathrm{A}}$ & $153 \pm 5^{\mathrm{A}}$ & $144 \pm 6^{\mathrm{A}}$ & $99 \pm 5^{\mathrm{B}}$
\end{tabular}

Values are means \pm SEM of five mice in each group. icv, intracerebroventricularly. ${ }^{\mathrm{A} S i g n i f i c a n t l y ~ g r e a t e r ~ t h a n ~} P C 2^{+/+}$value, $P<0.001 ;{ }^{\mathrm{B}}$ significantly less than other $P C 2^{-/-}$values, $P<0.001$ by repeated measures ANOVA.

through a central or a peripheral site of action. To do this, we injected small doses of the peptide intravenously and into the CNS. The results are presented in Table 2. In $\mathrm{PC}^{+/+}$mice $(n=5)$ who were normotensive after 1 week of the HSD, no significant effect of the peptide on MAP was observed, whether injected intravenously or intracerebroventricularly. $P C 2^{-/-}$were hypertensive; $60 \mathrm{fmol}$ of $\gamma$-MSH injected intravenously had no effect on MAP. Injection of $20 \mathrm{fmol}$ of the peptide intracerebroventricularly had an insignificant effect in lowering MAP $(153 \pm 5$ to $144 \pm 6 \mathrm{mmHg} ; P=\mathrm{NS})$. Injection of $60 \mathrm{fmol}$, however, caused MAP to fall profoundly to $99 \pm 5 \mathrm{mmHg}$, with $P<0.001$ versus all other values. Thus, a dose of $\gamma$-MSH that had no effect when administered intravenously restored MAP to near-normal levels when given into the cerebral ventricle.

We also tested the effect of continuous $\gamma$-MSH replacement on the development of salt-sensitive hypertension in $P C 2^{-/-}$mice. To do this, we inserted microosmotic pumps intra-abdominally as described in Methods in ten knockout mice. In five mice, the pumps were loaded with vehicle and the other five with NDP- $\gamma$-MSH, a stable analogue of $\gamma$-MSH with equal natriuretic potency (16). Mice then ingested the HSD for 1 week before undergoing measurement of MAP. In vehicle-administered mice, MAP was $159 \pm 5 \mathrm{mmHg}$, whereas in mice infused with NDP- $\gamma$-MSH, MAP was $92 \pm 4 \mathrm{mmHg}(P<0.001)$. Thus, continuous infusion of the $\gamma$-MSH analogue prevented the development of hypertension when the PC2 knockout mice were exposed to the HSD.

In five samples of plasma pooled from ten $\mathrm{PC}^{+/+}$mice on the LSD for 1 week, PRA was $5.8 \pm 1.1 \mathrm{ng} \mathrm{A} 1 / \mathrm{ml} / \mathrm{h}$ and was suppressed to $2.1 \pm 1.3 \mathrm{ng} \mathrm{A} 1 / \mathrm{ml} / \mathrm{h}$ in five other samples from mice on the HSD $(P=0.0683)$. Respective values in $P C 2^{-/-}$mice were $4.7 \pm 1.3$ (LSD) and $2.4 \pm 0.9$ (HSD) $\mathrm{ng} \mathrm{A} 1 / \mathrm{ml} / \mathrm{h}(P=0.1784)$. Corresponding values for plasma aldosterone concentration were $170 \pm 38.4$ (LSD, $n=5$ ) and $65.3 \pm 13.7(\mathrm{HSD}, n=5) \mathrm{pg} / \mathrm{ml}$ in $P C 2^{+/+}$ mice $(P<0.05)$ and $198 \pm 50.4(\mathrm{LSD}, n=4)$ and $76.8 \pm 11.0$ (HSD, $n=5) \mathrm{pg} / \mathrm{ml}$ in $P C 2^{-/-}$mice $(P<0.05)$.

$M c 3 r^{-1-}$ mice. We next examined the effect of 1 week of the HSD on MAP in mice lacking the $\gamma$-MSH receptor MC3R. As shown in Figure 3a, $\mathrm{Mc} \mathrm{r}^{+/+}$mice had a MAP of $78 \pm 2 \mathrm{mmHg}$ on the LSD and $82 \pm 2 \mathrm{mmHg}$ on the $\operatorname{HSD}(P=\mathrm{NS}) . M c 3 r^{-1}$ mice were normotensive on the LSD $\left(88 \pm 4 \mathrm{mmHg} ; P>0.05\right.$ versus $\left.M c 3 r^{+/+}\right)$, but, like the $\gamma$-MSH-deficient $P C 2^{-/-}$mice, were markedly hypertensive on the HSD $(145 \pm 2 \mathrm{mmHg}$; $P<0.001$ versus all other values). The plasma $\gamma-\mathrm{MSH}$ concentrations in these groups of mice are shown in Figure 3b. $\mathrm{Mc} 3 \mathrm{r}^{+/+}$mice had values slightly but not significantly lower than those observed in $\mathrm{PC}^{+/+}$mice, but, as in $\mathrm{PC}^{+/+}$mice, levels on the HSD were triple those on the LSD $(61.8 \pm 11.6$ versus $20.1 \pm 2.5 \mathrm{fmol} /$ $\mathrm{ml}, n=5$ for each group; $P<0.001)$. Plasma $\gamma$-MSH was higher on the LSD than the value observed in wildtype mice $(44.4 \pm 5.5 \mathrm{fmol} / \mathrm{ml}, P<0.01)$, but still increased on the HSD to $87.2 \pm 11.3 \mathrm{fmol} / \mathrm{ml}(P<0.05)$, a level that, however, was not significantly greater than the one seen in $\mathrm{Mc} \mathrm{r}^{+/+}$mice on the HSD $(P<0.10)$. Thus, these MC3R knockout mice also developed saltsensitive hypertension in a manner identical to the PC2 knockout mice, but had higher plasma $\gamma$-MSH concentrations rather than the low levels observed in the PC2 knockout mice. This observation is consistent with a hormone-resistance state.

In an effort to determine the effect of the anesthesia on our measurement of MAP, we studied five $\mathrm{Mc} \mathrm{r}^{-/-}$ mice fed the HSD for 1 week. MAP was recorded under anesthesia immediately after placement of the arterial catheter and was $149 \pm 5 \mathrm{mmHg}$. The mice were allowed to recover from anesthesia; $6 \mathrm{~h}$ later, MAP was again recorded and found to be $142 \pm 4 \mathrm{mmHg}(P=\mathrm{NS}$ versus value under anesthesia). This indicates that our technique for measuring MAP is not significantly distorted by the anesthetic agents we used.
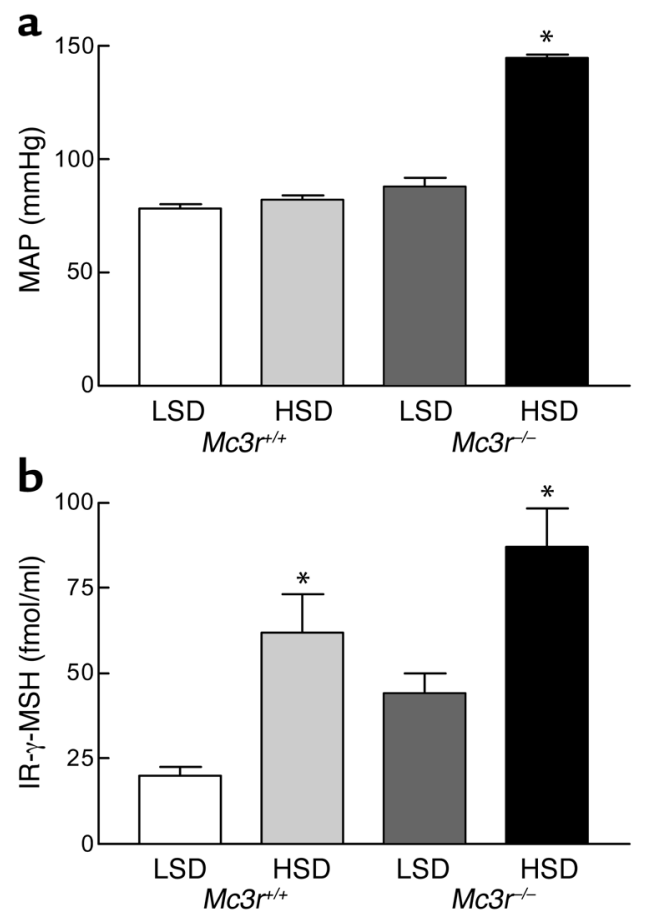

Figure 3

MAP (a) and plasma IR- $\gamma$-MSH concentration (b) after 1 week of a $\mathrm{LSD}$ or HSD in $\mathrm{Mc}^{3} \mathrm{r}^{+/+}$and $\mathrm{Mc}^{-1 /-}$ mice. Results are means \pm SEM of MAP in five mice in each group and of IR- $\gamma-\mathrm{MSH}$ concentration in five samples of plasma, each pooled from three mice. ${ }^{*} P<0.001$ versus all other values. 
We also tested the effect of MSH infusion in the

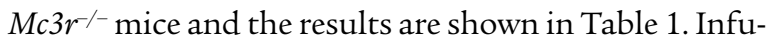
sion of neither $\alpha-\mathrm{MSH}$ nor $\gamma$-MSH into knockout mice on the HSD for 1 week had any effect on MAP or on $U_{\mathrm{Na}} V$, in contrast to results in PC2 knockout mice. These results indicate that the MC3R is necessary for $\gamma$-MSH to lower MAP in rodents ingesting the HSD and also is required for the natriuretic action of the peptide.

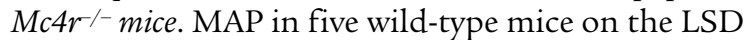
was $84 \pm 5 \mathrm{mmHg}$. In five $\mathrm{Mc}^{4-1-}$ mice ingesting the HSD for 1 week, MAP had no statistical difference at $88 \pm 7 \mathrm{mmHg}$. Although $\mathrm{Mc}^{4 r^{-1}}$ mice have an obese phenotype with insulin resistance (14), characteristics often associated with an elevated blood pressure, they do not develop salt-sensitive hypertension.

\section{Discussion}

The phenomenon of salt sensitivity of blood pressure has been frequently observed, but remains poorly understood, in part because only about one-half of hypertensive individuals exhibit it (18). It is variably thought to result from impaired renal sodium excretion from intrinsic renal disorders, or from dysregulation of the renin-angiotensin system, or heightened activity of the sympathetic nervous system, among other mechanisms (19-21). Despite redundancy in the pathways regulating renal sodium reabsorption and excretion, Mendelian forms of human hypertension caused by single gene defects all impact on renal-sodium handling (22), and it is also noteworthy that single gene deletion studies in rodents have also revealed the phenotype of salt-sensitive hypertension. For example, mice lacking the atrial natriuretic peptide $(A N P)$ gene $(23)$, the bradykinin $\mathrm{B}_{2}$ receptor (24), or the endothelin-B receptor (25) all exhibit saltsensitive hypertension. The results of our studies indicate that disruption of the $\gamma$-MSH system, currently not recognized to interact with those just mentioned, also causes major salt-sensitive hypertension, thereby offering further insight into the pathways by which salt sensitivity may develop as well as arguing for an important role of this system in normal sodium metabolism.

Earlier evidence indicated that the $\gamma$-MSH system is responsive to changes in dietary sodium intake. The plasma concentration of the peptide is increased when rats are placed on the $\operatorname{HSD}(5,6)$, and the pituitary content of $\gamma$-MSH immunoreactivity as well as the mRNA abundance of POMC also increase after exposure to the $\operatorname{HSD}(5,6)$. These changes are confined to the NIL, the lobe responsible for the processing of POMC into its smaller peptide products, and are accompanied by increases in the mRNA abundance of the processing enzymes necessary for cleavage of POMC into $\gamma$-MSH (6). The mouse displays a response comparable to the rat in that plasma $\gamma$-MSH concentration more than doubled in wild-type mice on the HSD for 1 week compared with the LSD. These observations all suggest a potential role for $\gamma$-MSH as a sodium-regulating hormone; however, they do not demonstrate that functioning of this system is required to maintain normal sodium homeostasis.
This issue consequently provided the rationale for studying the effects of $\gamma$-MSH deficiency or resistance on sodium metabolism using genetically altered mice.

PC2 null mice exhibited marked salt-sensitive hypertension: MAP during ingestion of the HSD was more than $50 \mathrm{mmHg}$ greater than that observed in wild-type mice or in knockout mice on the LSD (Figure 2). This hypertension was accompanied by a dramatic reduction in basal plasma $\gamma$-MSH concentration on the LSD to values only $10 \%$ of those seen in wild-type animals and a complete absence of any stimulation of peptide concentration in plasma when challenged with the HSD (Figure 2). Thus, although the residual immunoreactivity in plasma in knockout mice on the LSD may reflect alternate pathways of POMC processing, these alternate pathways do not respond in any measurable way to stimulation with the HSD. These data indicate that PC2 is necessary for most of the basal (unstimulated) level of plasma $\gamma$-MSH as well as all of the increase occurring in response to the HSD.

PC2-deficient mice might also be expected to have multiple abnormalities in prohormone processing in view of the widespread distribution of this enzyme and its identified role in peptide hormone secretion (26). Defects in prodynorphin, proglucagon, and prosomatostatin processing have been shown (13, 26-28), and altered POMC processing in the pituitary has been documented (29). It is thus possible that altered secretion of some other peptide involved in the regulation of blood pressure and $U_{\mathrm{Na}} V$ could exist besides $\gamma$-MSH to account for the development of hypertension while ingesting the HSD. Although this possibility cannot be refuted with certainty until more comprehensive measurements are made of the impact of dietary sodium intake on peptide hormone metabolism, several lines of evidence argue against it. First, infusion of $\gamma$-MSH to hypertensive $\gamma$-MSH-deficient $P C 2^{-/}$mice rapidly restored MAP to control levels, implying that the deficiency of the peptide in these mice was in some way responsible for the hypertension. Second, qualitatively and quantitatively similar hypertension developed in $\mathrm{Mc} 3 \mathrm{r}^{-/}$mice when exposed to the HSD. These mice actually had elevated levels of $\gamma$-MSH on both the LSD and the HSD, yet still developed salt-sensitive hypertension. Of the five melanocortin receptors identified to the present, $\gamma$-MSH binds with highest affinity to MC3R, which is thought to mediate its actions $(13,30$, 31). The occurrence of hypertension in MC3R knockout mice strengthens the contention that hypertension on the HSD results from disruption of the $\gamma$-MSH system, whether from impaired production and secretion, as in $P C 2^{-/-}$mice, or from impaired action, as in the receptordeficient ${\mathrm{Mc} 3 r^{-}-}^{-}$mice. Third, if another peptide pathway were involved, it would likely be impaired synthesis and secretion of a vasodilatory and natriuretic peptide such as ANP to cause the hypertension when ingesting the HSD. Although deletion of the ANP gene does result in salt-sensitive hypertension (23), there is no evidence that PC2 is involved in the processing of proANP and secretion of ANP by atrial myocytes (32). The processing of 
other vasodilatory peptides besides ANP could be involved in our results. Our observation that $\alpha-M S H$ infusion has no effect to lower MAP in hypertensive $P C 2^{-1-}$ mice, however, also suggests that the hypertension is a specific consequence of impaired processing of POMC into $\gamma-\mathrm{MSH}$, and its secretion and action through MC3R, even if the processing of POMC into other smaller peptides is also disrupted in these mice.

The results of these studies also provide new information regarding the natriuretic action of $\gamma-\mathrm{MSH}$. Although each of the MSH peptides has been known to be natriuretic $(9,10,33-35)$, the mechanism of this natriuresis has not been established, either with respect to nephron site of action or the transport system involved. Available data indicate that the natriuresis occurs on intrarenal infusion of the peptide, without change in MAP or glomerular filtration rate, and is interrupted by acute renal denervation $(9,10)$. The present data indicate that intravenous $\gamma$-MSH is natriuretic in $\mathrm{PC}^{-/-}$mice with intact melanocortin receptors, but not in $\mathrm{Mc}^{3-/-}$ mice lacking the receptor with which the peptide interacts. The failure of $\alpha-\mathrm{MSH}$ infusion to cause natriuresis is somewhat surprising given its affinity to MC3R in vitro (13); this lack of natriuretic activity strengthens the contention that $\gamma$-MSH is the POMC-derived peptide involved in sodium homeostasis. MC3Rs have been identified in human (36) and rat (37) kidney, and our results demonstrate that it is this receptor that mediates the natriuresis caused by the peptide. Since neither $\alpha$-nor $\gamma$-MSH was natriuretic in $\mathrm{Mc} 3 r^{-/}$mice, it does not appear that other renal melanocortin receptors are involved in the natriuresis. Finally, $\gamma$-MSH led to equivalent natriuresis in wild-type and $P C 2^{-/-}$mice (Table 1 ); to the extent that the natriuretic response can be used as an index of receptor activity or expression, this argues against the possibility that deficiency of the hormone led to upregulation of $\mathrm{Mc} 3 \mathrm{r}$ in the kidney. This question will obviously have to be addressed in studies directly measuring the renal expression of the melanocortin receptors in these different mouse models.

The mechanism by which the HSD results in hypertension in $\mathrm{PC}^{-/-}$and $\mathrm{Mc}^{-r^{-/}}$mice is not clear from these studies. One possibility is that the natriuresis resulting from $\gamma$-MSH infusion leads to a reduction in plasma volume and a consequent lowering of MAP. Against this is the rapidity of the fall in MAP with only a doubling of $U_{\mathrm{Na}} V$ so that a large reduction in plasma volume would not have occurred. Given our evidence of a central site of action of $\gamma$-MSH to lower MAP (Table 2), it may be that this mechanism interacts with the natriuresis in the long-term regulation of MAP. Altered regulation of the renin-angiotensin system should also be considered as a component of the saltsensitive hypertension we have observed. The limited data we have obtained suggest that PRA and plasma aldosterone concentration are suppressed by the HSD to an equal extent in wild-type and $P C 2^{-/-}$mice, even though, in the case of the former, this suppression was not significant statistically because of the large variance in the samples assayed. Furthermore, there is no evidence of PC2 involvement in prorenin processing (38). Studies examining the effect of an angiotensin receptor antagonist on blood pressure in the hypertensive mice would address more directly any contribution of circulating angiotensin II to the hypertension.

A third mechanism could be activation of the sympathetic nervous system by the HSD in peptide- or receptordeficient mice. In this formulation, $\gamma$-MSH acting through central Mc3r exerts a tonic inhibition of sympathetic outflow developing in response to the HSD; deficiency of the hormone ( $P C 2^{-/-}$mice) or blunted responsiveness $\left(M c 3 r^{-1-}\right.$ mice $)$ then allows this increased outflow to go unchecked, resulting in hypertension. Infused $\gamma$-MSH could gain access to the CNS via the circumventricular organs that lie outside the blood-brain barrier; the peptide could thereby restore central inhibition of sympathetic outflow. Our observation that intracerebroventricular administration of $\gamma$-MSH lowered MAP at a dose that had no effect when given intravenously (Table 2) supports such a mechanism. This hypotensive action of the peptide actually is opposite that of published action of $\gamma$-MSH in the CNS, where it has been reported to stimulate sympathetic outflow, increase MAP, and produce tachycardia in most (reviewed in ref. 30, 31, 39) but not all (40) reports. One study, however, has observed a hypotensive and bradycardic action of the peptide when injected directly into the nucleus of the tractus solitarius of the rat (41). Since this is one of the circumventricular organs, it is possible that it mediates the hypotensive effect of the intravenous $\gamma$-MSH infusion in hypertensive $P C 2^{-/-}$mice. These conflicting reports, and other data on the central actions of $\gamma$-MSH, have led to the speculation that another, as yet unidentified, melanocortin receptor mediates the cardiovascular actions of the peptide (42). This inference notwithstanding, our results clearly show that its hypotensive action in hypertensive, salt-loaded $P C 2^{-/-}$mice occurs through $\mathrm{Mc} 3 \mathrm{r}$, since it is not observed in the Mc3r knockout mice. Although the rapidity with which $\gamma$-MSH corrects the hypertension in salt-loaded $P C 2^{-/-}$mice suggests the possibility of a direct effect on resistance blood vessels, the hypotension observed following intracerebroventricular injection of the peptide (Table 2) makes this unlikely as a major mechanism.

The relevance of these observations to human saltsensitive hypertension remains to be established. In contrast to rodents, humans do not have a clearly defined pituitary intermediate lobe. Cells can be identified in the human pituitary, however, with histochemical and immunocytochemical characteristics of melanotrophs $(39,43-45)$, and $\gamma$-MSH-like immunoreactivity has been identified in human plasma, although not fully characterized $(46,47)$. Some years ago, Griffing and colleagues proposed that this peptide may be involved in the pathogenesis of some forms of idiopathic hyperaldosteronism (46). Mineralocorticoidinduced hypertension, however, does not seem to account for the salt sensitivity of $P C 2^{-/-}$mice, since plasma aldosterone concentration was suppressed by 
the HSD in the knockouts to the same extent as in the wild-type mice. The plasma concentration of $\gamma-\mathrm{MSH}$ was also observed to be elevated in patients with severe heart failure (47). Additionally, components of this peptide system are found in many human tissues (30). It thus seems plausible to entertain the possibility that the $\gamma$-MSH system may be part of the integrated response to increases in dietary sodium intake and that derangements in this system may be implicated in some cases of salt-sensitive hypertension.

\section{Acknowledgments}

We would like to acknowledge the assistance of Baoji $\mathrm{Xu}$, Department of Physiology, University of California, San Francisco, in the conduct of the experiments involving the injection of $\gamma$-MSH into the cerebral ventricle. This work was supported by grants DK58812 and HL-68871 to M.H. Humphreys, DK-56695 to D. Pearce, and DK-55819 and DK-51730 to R.D. Cone, all from the NIH.

1. Kurtz, I. 2001. Control of sodium excretion. In Textbook of Nephrology. 4th edition. S.G. Massry and R.J. Glassock, editors. Lippincott Williams \& Wilkins. Philadelphia, Pennsylvania, USA. 254-261.

2. Humphreys, M.H., and Valentin, J.-P. 2000. Natriuretic humoral agents. In The kidney: physiology and pathophysiology. 3rd edition. Lippincott Williams \& Wilkins. Philadelphia, Pennsylvania, USA. 1371-1410.

3. Carey, R.M. 2001. Renal dopamine system. Paracrine regulator of sodium homeostasis and blood pressure. Hypertension. 38:297-302.

4. Katori, M., Majima M., and Hyashi, I. 1998. Crucial suppressive role of renal kallikrein-kinin system in development of salt-sensitive hypertension. Biol. Res. 31:143-149.

5. Mayan, H., et al. 1996. Dietary sodium intake modulates pituitary proopiomelanocortin mRNA abundance. Hypertension. 28:244-249.

6. Chandramohan, G., Ni, X.-P., Kalinyak, J.E., and Humphreys, M.H. 2001. Dietary sodium modulates mRNA abundance of enzymes involved in pituitary processing of proopiomelanocortin. Pituitary. 4:231-237.

7. Zhou, A., Bloomquist, B.T., and Mains, R.E. 1993. The prohormone convertases PC1 and PC2 mediate distinct endoproteolytic cleavages in a strict temporal order during proopiomelanocortin biosynthetic processing. J. Biol. Chem. 268:1763-1769.

8. Benjannet, S., Rondeau, N., Day, R., Chretien, M., and Seidah, N.G. 1991. $\mathrm{PC} 1$ and $\mathrm{PC} 2$ are proprotein convertases capable of cleaving proopiomelanocortin at distinct pairs of basic residues. Proc. Natl. Acad. Sci. U. S. A. 88:3564-3568.

9. Lin, S.Y., Chaves, C., Wiedemann, E., and Humphreys, M.H. 1987. A $\gamma$-melanocyte stimulating hormone-like peptide causes reflex natriuresis after acute unilateral nephrectomy. Hypertension. 10:619-627.

10. Chen, X.-W., et al. 1997. Mechanism of the natriuretic action of $\gamma$-melanocyte-stimulating hormone. Am. J. Physiol. 272:R1946-R1953.

11. Butler, A.A., et al. 2000. A unique metabolic syndrome causes obesity in the melanocrotin-3 receptor-deficient mouse. Endocrinology. 141:3518-3521.

12. Furuta, M., et al. 1997. Defective prohormone processing and altered pancreatic islet morphology in mice lacking active SPC2. Proc. Natl. Acad. Sci. U. S. A. 94:6646-6651.

13. Roselli-Rehfuss, L., et al. 1993. Identification of a receptor for $\gamma$-melanotropin and other proopiomelanocortin peptides in the hypothalamus and limbic system. Proc. Natl. Acad. Sci. U. S. A. 90:8856-8860.

14. Huszar, D., et al. 1997. Targeted disruption of the melanocortin-4 receptor results in obesity in mice. Cell. 88:131-141.

15. Ackermann, U., and Azizi, N. 2000. Increased central $A T_{1}$-receptor activation, not systemic vasopressin, sustains hypertension in ANP knockout mice. Am. J. Physiol. 278:R1441-R1445.

16. Sawyer, T.K., et al. 1980. 4-Norleucine, 7-D-phenylalanine- $\alpha$-melanocyte stimulating hormone: a highly potent $\alpha$-melanotropin with ultralong biological activity. Proc. Natl. Acad. Sci. U. S. A. 77:5754-5758.

17. Ni, X.-I., et al. 1998. Prevention of reflex natriuresis after acute unilateral nephrectomy by melanocortin receptor antagonists. Am. J. Physiol. 274:R931-R938.

18. Weinberger, M.H. 1996. Salt sensitivity of blood pressure in humans. Hypertension. 27:481-490.
19. Johnson, R.J., Herrera-Acosta, J., Schreiner, G.F., and Rodriguez-Iturbe, B. 2002. Subtle acquired renal injury as a mechanism of salt-sensitive hypertension. N. Engl. J. Med. 346:913-923.

20. Campese, V.M. 1994. Salt sensitivity in hypertension. Renal and cardiovascular implications. Hypertension. 23:531-550.

21. Muntzel, M., and Drueke, T. 1992. A comprehensive review of the salt and blood pressure relationship. Am. J. Hypertens. 5:1S-42S.

22. Lifton, R.P., Gharavi, A.G., and Geller, D.S. 2001. Molecular mechanisms of human hypertension. Cell. 104:545-556.

23. John, S.W., et al. 1995. Genetic decreases in atrial natriuretic peptide and salt-sensitive hypertension. Science. 267:679-681.

24. Alfie, M.E., Yang, X.-P., Hess, F., and Carretero, O.A. 1996. Salt-sensitive hypertension in bradykinin B2 receptor knockout mice. Biochem. Biophys. Res. Commun. 224:625-630.

25. Gariepy, C.E., Ohuchi, T., Williams, S.C., Richardson, J.A., and Yanagisawa, M. 2000. Salt-sensitive hypertension in endothelin-B receptor-deficient rats. J. Clin. Invest.105:925-933.

26. Zhou, A., Webb, G., Zhu, X., and Steiner, D.F. 1999. Proteolytic processing in the secretory pathway. J. Biol. Chem. 274:20745-20748.

27. Berman, Y., et al. 2000. Defective prodynorphin processing in mice lacking prohormone convertase PC2. J. Neurochem. 75:1763-1770.

28. Furuta, M., et al. 2001. Severe defect in proglucagon processing in islet A-cells of prohormone convertase 2 null mice. J. Biol. Chem. 276:27197-27202.

29. Allen, R.G., et al. 2001. Altered processing of pro-orphanin FQ/nociceptin and proopiomelanocortin-derived peptides in the brains of mice expressing defective prohormone convertase 2. J. Neurosci. 21:5864-5870.

30. Wikberg, J.E.S., et al. 2000. New aspects on the melanocortins and their receptors. Pharmacol. Res. 42:393-420.

31. Schioth, H.B. 2001. The physiological role of melanocortin receptors. Vitam. Horm. 63:195-232.

32. Yan, W., Wu, F., Morser, J., and Wu, Q. 2000. Corin, a transmembrane cardiac serine protease, acts as a pro-atrial natriuretic peptide-converting enzyme. Proc. Natl. Acad. Sci. U. S. A. 97:8525-8529.

33. Orias, R., and McCann, S.M. 1972. Natriuresis induced by alpha and beta melanoctye stimulating hormone (MSH) in rats. Endocrinology. 90:700-706.

34. Hradec, J., and Horky, K. 1979. Natriuretic and kaliuretic effect of melanocyte stimulating hormones in hamster. Endocrinol. Exp. 13:145-152.

35. Lymangrover, J.R., Buckalew, V.M., Harris, J., Klein, M.C., and Gruber, K.A. 1984. Gamma-2 MSH is natriuretic in the rat. Endocrinology. 116:1227-1229.

36. Chhajlani, V. 1996. Distribution of cDNA for melanocortin receptor subtypes in human tissues. Biochem. Mol. Biol. Int. 38:73-80.

37. Ni, X.-P., Bhargava, A., Pearce, D., and Humphreys, M.H. 2002. Dietary sodium intake modulates renal expression of melanocortin 3 receptor (MC3-R) mRNA and protein abundance in the rat. J. Am. Soc. Nephrol. 13:81A. (Abstr.)

38. Laframboise, M., et al. 1997. Prorenin activation and prohormone convertases in the mouse As4.1 cell line. Kidney Int. 51:104-109.

39. Gruber, K.A., and Callahan, M.F. 1989. ACTH-(4-10) through $\gamma-\mathrm{MSH}$ : evidence for a new class of central autonomic nervous system-regulating peptides. Am. J. Physiol. 257:R681-R694.

40. De Wildt, D.J., Krugers, H., Kasbergen, C.M., De Lang, H., and Versteeg, D.H.G. 1993. The hemodynamic effects of $\gamma_{2}$-melanocyte stimulating hormone and related melanotropins depend on the arousal potential of the rat. Euro. J. Pharmacol. 233:157-164.

41. De Wildt, D.J., Van Der Ven, J.C., Van Bergen, P., De Lang, H., and Versteeg, D.H.G. 1994. A hypotensive and bradycardic action of $\gamma_{2}$-melanocyte stimulating hormone $\left(\gamma_{2}\right.$-MSH) microinjected into the nucleus tractus solitarii of the rat. Naun. Schmied. Arch. Pharmacol. 349:50-56

42. Li, S.-J., et al. 1996. Melanocortin antagonists define two distinct pathways of cardiovascular control by $\alpha$ - and $\gamma$-melanocyte stimulating hormones. J. Neurosci. 16:5182-5188.

43. Wilkes, N.M., Watkin, S., Stewart, R.D., and Yen, S.S.C. 1980. Localization and quantitation of $\beta$-endorphin in human brain and pituitary. Neuroendocrinology. 30:113-121.

44. Ali-Rachedi, A., et al. 1983. Immunocytochemical evidence for the presence of $\gamma$-MSH-like immunoreactivity in pituitary corticotrophs and ACTH-producing tumors. Neuroendocrinology. 37:427-433.

45. Franco-Saenz, R., Mulrow, P.J., and Kim, K. 1984. Idiopathic aldosteronism: a possible disease of the intermediate lobe of the pituitary. J. Am. Med. Assoc. 251:2555-2558.

46. Griffing, G.T., et al. 1985. Plasma immunoreactive gamma melanotropin in patients with idiopathic hyperaldosteronism, aldosterone-producing adenomas, and essential hypertension. J. Clin. Invest. 76:163-169.

47. Ekman, R., Bjartell, A., Lisander, B., and Edvinsson, L. 1989. $\gamma_{2}-\mathrm{MSH}$ immunoreactivity in the human heart. Life Sci. 45:787-792. 